\title{
Aggregate Labor Force Participation and Unemployment and Demographic Trends
}

\author{
Andreas Hornstein \\ Federal Reserve Bank of Richmond \\ Marianna Kudlyak \\ Federal Reserve Bank of San Francisco
}

February 2019

Working Paper 2019-07

https://www.frbsf.org/economic-research/publications/working-papers/2019/07/

\section{Suggested citation:}

Hornstein, Andreas, Marianna Kudlyak. 2019. “Aggregate Labor Force Participation and Unemployment and Demographic Trends,” Federal Reserve Bank of San Francisco Working Paper 2019-07. https://doi.org/10.24148/wp2019-07

The views in this paper are solely the responsibility of the authors and should not be interpreted as reflecting the views of the Federal Reserve Bank of San Francisco or the Board of Governors of the Federal Reserve System. 


\title{
Aggregate Labor Force Participation and Unemployment and Demographic Trends*
}

\author{
Andreas Hornstein Marianna Kudlyak \\ FRB Richmond FRB San Francisco
}

February 28, 2019

\begin{abstract}
We estimate trends in the labor force participation (LFP) and unemployment rates for demographic groups differentiated by age, gender, and education, using a parsimonious statistical model of age, cohort and cycle effects. Based on the group trends, we construct trends for the aggregate LFP and unemployment rate. Important drivers of the aggregate LFP rate trend are demographic factors, with increasing educational attainment being important throughout the sample and ageing of the population becoming more important since 2000, and changes of groups' trend LFP rates, e.g. for women prior to 2000. The aggregate unemployment rate trend on the other hand is almost exclusively driven by demographic factors, with about equal contributions from an older and more educated population. Extrapolating the estimated trends using Census Bureau population forecasts and our own forecasts for educational shares, we project that over the next 10 years the trend LFP rate will decline to $61.1 \%$ from its 2018 value of $62.7 \%$, and the trend unemployment rate will decline to $4.3 \%$ from its 2018 value of $4.7 \%$.
\end{abstract}

Keywords: Labor Force Participation Rate. Unemployment Rate. Demographic Composition. Age Effects. Cohort Effects. Educational Attainment.

\footnotetext{
*Any opinions expressed are those of the authors and do not reflect those of the Federal Reserve Bank of Richmond, the Federal Reserve Bank of San Francisco or the Federal Reserve System. E-mail addresses: andreas.hornstein@rich.frb.org, marianna.kudlyak@sf.frb.org.
} 


\section{Introduction}

Researchers and policymakers are very interested in decomposing the unemployment rate and the labor force participation (LFP) rate into their long-run trends and more transitory cyclical components. Deviations of these rates from their long run trends serve as a signal of the labor market's health. Most of this discussion proceeds at an aggregate level, but unemployment and LFP rates differ systematically across demographic groups defined by age, gender and education. ${ }^{1}$ Unemployment rates tend to be lower for older and more educated workers, labor force participation rates tend to be lower for older and less educated workers, and historically men tend to have lower unemployment rates and higher LFP rates than women. The aggregate unemployment and LFP rates are functions of population-share weighted sums of the demographic groups' rates. Similarly, the trend in the aggregate rates depends on the weighted sum of the trends of the groups' rates. Given the differences in the rates across demographic groups, changes in demographic composition of the population change the aggregate trend rate, even if the trend rates of the demographic groups remain unchanged.

In this article, we estimate trends for the LFP and unemployment rates of demographic groups defined by age, gender and education, and we use these trends, together with the groups' population shares, to construct the trends of the aggregate LFP and unemployment rate. We estimate the groups' trends using a parsimonious statistical model of age, cohort, and cycle effects, and we define the trend as the sum of the age and cohort effects. The estimated trend in the aggregate unemployment rate declined almost monotonically from $7 \%$ in 1976 to $4.7 \%$ in 2017, and the cyclical deviations of unemployment from its trend are substantial. The decline in the trend unemployment rate is almost exclusively driven by demographic factors, about equal contributions from an older and more educated population. The estimated trend in the aggregate LFP rate is hump-shaped with a peak in 2000, and cyclical deviations from its trend tend to be small. The trend LFP rate is not only driven by demographics, with increasing educational attainment being important throughout the sample and ageing of the population becoming more important since 2000, but also by changes of groups' trend LFP rates, e.g., for women prior to 2000.

We construct ten year forecasts of the unemployment and LFP rate trend using population projections for age-gender groups and a simple cohort model of age-gender contingent educational attainment. We take the population projections from the CBO (2018) and estimate the educational attainment model for our sample. The trend projections for the aggregate LFP and unemployment rate depend on the assumptions made for the model.

\footnotetext{
${ }^{1}$ See our illustrative example in Section 2 below.
} 
Using our preferred model, we project that over the next ten years the trend LFP rate will decline another $1.6 \mathrm{ppts}$ from its current value of 62.7 percent, and the trend unemployment rate will decline by 0.4 ppts from its current value of 4.7 percent. If instead we fix the age-gender contingent educational shares at their 2018 levels, the LFP rate trend projection declines an additional 0.8 ppts, but the unemployment rate trend declines 0.2 ppts less.

Our approach, building up the trend of the aggregate LFP rate from trend estimates of group-specific age-cohort models, is not new. The existing literature has used age-cohort models of demographic groups' supplemented by a large number of additional controls, e.g. Aaronson, Cajner, Fallick, Galbis-Reig, Smith, and Wascher (2014). ${ }^{2}$ Typically, the time variation of the age-specific rate of a demographic group is attributed to cohort effects and the age effect is taken as fixed. But age-specific rates vary quite a bit more than can be accounted for by cohort effects. For example, older workers participate at higher rates in the labor market now than two decades ago; young workers, 16-24 years old, participate at a much lower rate than in the 1990s. Augmenting the model with group LFP rates that depend on additional controls, such as school enrollment, social security payouts and others helps capture the evolving age effects. Our alternative approach is to allow for time variation in age effects, while being explicit about the stochastic processes that drive age and cohort effects. Like Montes (2018) we differentiate our demographic groups by education, rather than including educational attainment as an additional control.

Another paper closely related to our work is Barnichon and Mesters (2018) who estimate the trend unemployment rate. ${ }^{3}$ They emphasize that the aggregate unemployment rate is jointly determined by the trends in group unemployment and LFP rates, and that changes in a demographic group's trend unemployment rate are likely related to changes in its trend LFP rate. For this reason Barnichon and Mesters (2018) estimate a dynamic factor model for labor force status transition rates which jointly determine LFP and unemployment rates. For demographic groups defined by age and gender they argue that accounting for the joint determination of unemployment and LFP trends significantly affects the estimated trend for the aggregate unemployment rate. We will argue that, despite some notable changes for groups' trend LFP rates, changes in population shares play a larger role for the aggregate unemployment rate trend once one also takes into account demographic trends in educational

\footnotetext{
${ }^{2}$ Related papers that use age-cohort models of demographic groups to study the aggregate LFP rate are Aaronson, Fallick, Figura, Pingle, and Wascher (2006), Fallick and Pingle (2007), Balleer, Gomez-Salvador and Turunen (2009), Kudlyak (2013), and Montes (2018). Recent work on the cyclicality of the aggregate LFP rate, ignoring demographic aspects, includes Tuzemen and Van Zandweghe (2018) and Cairó, Shigeru, and Morales-Jiménez (2019).

${ }^{3}$ For other papers that have studied the role of demographics for the aggregate unemployment rate see, for example, Shimer (1998) and Elsby, Hobijn and Sahin (2010).
} 
attainment.

The rest of the paper is structured as follows. Section 2 illustrates the systematic differences of unemployment and LFP rates for a coarse decomposition of the U.S. population. Section 3 describes the estimation framework, including notes on the data. Section 4 describes the results for the estimates of cycle and trend of the unemployment rate and LFP rate across demographic groups. Section 5 describes the results for the trend of the aggregate LFP rate and unemployment rate. Section 6 provides ten year projections of the aggregate LFP and unemployment rate based on a cohort model of educational attainment. Section 7 concludes.

\section{Demographics of the Labor Market, 1979 and 2018}

Before we provide a formal analysis of the differences in labor market outcomes across demographic groups and how they change over time, Table 1 illustrates these differences for a coarse decomposition of the U.S. population aged 25 and older. We use the micro CPS data to calculate annual averages of unemployment and LFP rates, and population shares. We split the population by age, less than 55 years old versus 55 years and older, gender, men versus women, and education, high school or less versus some college or more. Data are available for the years 1976 to 2018. In order to see how group rates have changed over time absent business cycle effects, we calculate the rates and population shares for the two years, 1979 and 2018, which represent the aggregate unemployment rate troughs at the beginning and end of our sample.

Panel (A) illustrates that the unemployment rate is lower for more educated workers and that it tends to be lower for older workers. Over time it appears that the unemployment rate has increased for men and for older women, but changes have been small, less than one percentage point for any of the demographic groups. Panel (B) illustrates that the LFP rate is lower for less educated workers, for older workers, and for women. Over time the LFP rate has decreased for men and increased for women, independent of education and age, and changes have been noticeable, between 5 and 10 percentage points.

Finally, from Panel (C) we can see that over time the U.S. population has gotten older, the share of those older than 55 years increased by about 7 percentage points, and more educated, the share of those with more than a high school education increased by about 30 percentage points. Holding group unemployment rates and LFP rates fixed, the shift towards an older and more educated population lowers the aggregate unemployment rate. For the LFP rate these same two demographic shifts have opposing effects. In what follows we will construct trend measures of the demographic groups' unemployment and LFP rates 
and then attribute changes in the aggregate trends to changes in trend group rates and demographic shifts.

\section{Framework for Trend Estimates}

In this section, we describe our simple model of trend and cycle for demographic groups. Suppose we have observations on the outcome $q$ (labor force participation rate or unemployment rate) and the population share $p$ of demographic group $i$ at time $t$ for age groups $a$ or cohorts $t-a$

$$
\begin{aligned}
Q_{i} & =\left\{q_{a, i, t}: t=1, \ldots, T \text { and } a=1, \ldots A\right\} \\
P_{i} & =\left\{p_{a, i, t}: t=1, \ldots, T \text { and } a=1, \ldots A\right\}
\end{aligned}
$$

For a particular demographic group we write the observed outcome for its age groups as a linear function of unobserved cohort effects, $x$, age effects, $y$, and cycle/time effects, $z$,

$$
q_{a, i, t}=x_{a, i, t}+y_{a, i, t}+z_{a, i, t}+\varepsilon_{a, i, t}^{q} \text { with iid } \varepsilon_{a, i, t}^{q} \sim N\left(0, \sigma_{a, i, q}^{2}\right)
$$

We assume stochastic processes for age, cohort, and cycle effects that are independent across demographic groups and will drop the group index when no confusion can arise. In particular, we assume that the age and cohort effects follow random walks

$$
\begin{aligned}
& x_{1, t}=x_{1, t-1}+\varepsilon_{1 t}^{x} \text { with iid } \varepsilon_{1 t}^{x} \sim N\left(0, \sigma_{1 x}^{2}\right) \\
& x_{a, t}=x_{a-1, t-1} \text { for } a>1 \\
& y_{a, t}=y_{a, t-1}+\varepsilon_{a, t}^{y} \text { with iid } \varepsilon_{a, t}^{y} \sim N\left(0, \sigma_{a y}^{2}\right) \text { for } a \geq 1 .
\end{aligned}
$$

The initial cohort effect of a new cohort is a random variation of the initial effect of the new cohort in the previous period. We assume that the cohort effect remains fixed over the life time of a cohort, that is, cohort effects are fixed birth-year cohort effects.

There is a common cyclical effect to all age groups of a demographic group and this cyclical effect can be latent or observed. For group unemploymen rates we assume that the cyclical effect is latent and follows an $\operatorname{AR}(1)$ process

$$
z_{t}=\rho z_{t-1}+\varepsilon_{t}^{z} \text { with iid } \varepsilon_{t}^{z} \sim N\left(0, \sigma_{z}^{2}\right) \text { and }\|\rho\|<1
$$

For a group's labor force participation rate we assume that we observe a noisy signal of the cyclical effect, in particular, we take the smoothed posterior estimate of the cyclical effect for the group's unemployment rate as the signal. 
For group unemployment rates the impact of the cyclical effect on an age group is simply

$$
z_{a, t}=\gamma_{a} z_{t}
$$

The coefficients $\gamma$ capture systematic age-related differences in the response to the common cyclical component, and we normalize the impact on the first age group, $\gamma_{1} \equiv 1 .{ }^{4}$ For group labor force participation rates we assume that the cyclical effect is a moving average of the lagged observed cyclical unemployment effects, and that there are again systematic age-related differences in the response to the common cyclical effect,

$$
z_{a, t}=\gamma_{a} \sum_{s=0}^{n} \rho_{s} z_{t-s}
$$

For this specification there is no need to normalize $\gamma$.

The trend of a group's outcome is the sum of the persistent age and cohort effects,

$$
q_{a, t}^{T}=x_{a, t}+y_{a, t}
$$

We apply our model to annual averages of observable outcomes and population shares, and we aggregate our cohorts into age groups 16-19, 20-24, 25-34, etc. Thus the observation equation for age group $g$ that contains ages $a \in A_{g}$ is

$$
\bar{q}_{g, t}=\frac{1}{\# A_{g}} \sum_{a \in A_{g}} x_{a, t}+\bar{y}_{g, t}+\bar{z}_{g, t}+\bar{\varepsilon}_{g, t}^{q} .
$$

The transition equations for annual cohort effects remain as they are, but the transition equations for the age and cycle effects now apply to time-averaged age groups, not individual age groups. ${ }^{5}$

We use maximum likelihood to estimate the parameters $\Theta=\left\{\sigma_{\bar{q}, g}, \sigma_{x}, \sigma_{\bar{y}}, \sigma_{\bar{z}}, \rho, \gamma_{g}\right\}$ if the cycle component is not observed, and the parameters $\Theta=\left\{\sigma_{\bar{q}, g}, \sigma_{x}, \sigma_{\bar{y}}, \gamma_{g, s}\right\}$ if we observe the cycle component. We estimate the unobserved state (age, cohort, and cycle) using the Kalman filter conditional on parameters $\Theta$. For each demographic group defined by gender and education our estimation proceeds in two steps. First, we estimate the model for the group's unemployment rate assuming that the cycle effect $z_{t}^{u}$ is not observed. Second, we estimate the model for the group's labor force participation rate, taking the smoothed

\footnotetext{
${ }^{4}$ Alternatively, we could have normalized the variance of the innovation to the common cyclical component, $\sigma_{z}^{2}$.

${ }^{5}$ We will apply our model to the levels of unemployment and LFP rates. Alternatively, we could apply the model to the log levels of the rates, which would mean that the calculate geometric averages for the age groups.
} 
posterior estimate of the group's cyclical effect for its unemployment rate as a noisy signal of the true effect. We use this procedure since labor force participation rates are highly persistent and we have not been succesful in estimating a stationary cyclical effect directly. ${ }^{6}$

Given the random walk nature of our cohort and age group effects we define the trend of a group as the sum of the estimated age and cohort effects

$$
\bar{q}_{g, i, t}^{T}=\frac{1}{\# A_{g, i}} \sum_{a \in A_{g, i}} x_{a, i, t}+\bar{y}_{g, i, t} .
$$

We use the smoothed posteriors for our estimates of the age and cohort effects. The trend of the aggregate LFP rate is then the population share weighted sum of the groups' trend LFP rates

$$
l_{t}^{T}=\sum_{g, i} p_{g, i, t} \bar{l}_{g, i, t}^{T},
$$

and the trend of the aggregate unemployment rate is

$$
u_{t}^{T}=\frac{\sum_{g, i} p_{g, i, t} \bar{l}_{g, i, t}^{T} \bar{u}_{g, i, t}^{T}}{\sum_{g, i} p_{g, i, t} \bar{l}_{g, i, t}^{T}}
$$

For this purpose, we treat the population shares of different groups as exogenous.

\subsection{Data and empirical implementation}

The data in the analysis are constructed from the monthly basic files of the Current Population Survey (CPS) from January 1976 to October 2018. We use the CPS labor status variable to classify each member of the civilian non-institutionalized population of age 16 or older as employed, unemployed or out of the labor force. We aggregate the individual micro data into age-gender-education cells using the CPS-provided sampling weights. Finally, for each cell we construct the unemployment rate, the LFP rate and population shares. ${ }^{7}$

The age groups are 16-19, 20-24, 25-34, 35-44, 45-54, 55-64, and 65 years and older. The educational categories for those aged 25 and older are less than high school, high school, some college, and college or higher. Note that we do not differentiate the young, those aged 24 or less, by education. Consequently, we have 44 age-gender-education cells.

\footnotetext{
${ }^{6}$ In Appendix 8.1 we provide a more detailed description of the state-space model for a demographic group's LFP rate.

${ }^{7}$ We use the micro data from the CPS. For the aggregation of individual observations we use the composite final weights used to produce BLS published labor force statistics available from 1998 on, and the final weights otherwise. Our aggregate unemployment rate replicates the one published by the BLS for the full sample, but there are some minor deviations, not exceeding $0.2 \mathrm{ppts}$, of our aggregate LFP rate from the one published by the BLS for the years prior to 2002. Our data for 2018 represent the average for the months up to and including October.
} 
We estimate our state-space model separately for young men and women, not differentiated by education, and for each gender and education group for individuals aged 25 and older. To forecast the trend, we need a forecast of the population shares and a forecast of the trend unemployment and LFP rates. We use our estimates of the trend to construct groups' trend forecasts. We use population forecasts to construct population shares by age and gender. ${ }^{8}$ We then estimate a cohort-age model of educational attainment to construct a forecast of the age-gender shares by education.

\section{Demographics of Unemployment and LFP}

We now apply our framework to the unemployment rates and LFP rates of the demographic groups defined bye age, gender, and education and characterize their trend and cycle. We find that group unemployment rates move together over the cycle, the least (most) educated group is the most (least) volatile, and volatility declines with age. Group LFP rates are not very cyclical, except for those 16-19 years old whose LFP rate is strongly pro-cylical, and the oldest college educated group whose LFP rate is strongly counter-cyclical.

Removing the cyclical components we find not much of a change in the trend values of the group unemployment rates. To the extent that group unemployment trends change there is no uniform pattern to the contributions of age and cohort effects. Turning to group LFP rates we find large and systematic changes in their trends: for those younger than 25 years LFP rates declined for men and women alike, and for those 25 years and older the LFP rates of men declined and the LFP rates of women increased. Again, age and cohort effects contribute about equally to these changes, with cohort effects being somewhat more prevalent among women. While error bounds for estimates of group trend LFP rates are quite narrow, trend unemployment rates are subject to large uncertainty.

\subsection{Unemployment rates: cycle and trend}

The common cyclical components of the different demographic groups' unemployment rates move together and therefore with the aggregate unemployment rate. Figure 1 displays the common cycle effects by education for men (top panel) and women (bottom panel). With respect to education, the least educated group (less than high school) is the most cyclically volatile and the most educated group (college or higher) is the least cyclically volatile group.

\footnotetext{
${ }^{8}$ Specifically we use the Bureau of the Census (2018) population projections based on the middle assumptions for future fertility, life expectancy and net immigration levels as of July 1 of each year. Downloaded from Haver.
} 
The cyclical volatilities of the other two education groups and those less than 25 years old are bracketed by these two groups. This characterization applies to both men and women, with the womens' cycle effects being somewhat less volatile. Finally, comparing across recession episodes, we find that for all groups the cyclical unemployment factor reached a higher level during the 2007-09 recession than in all other recessions. This is most noticeable for the highest educated group which has never moved much over the cycle except for the 2007-09 recession.

With respect to age, older groups are less cyclically sensitive than younger groups for all education levels. Table 2 displays the estimated age-coefficients on the common cyclical factor by education for men (top panel) and women (bottom panel). For all groups the coefficient on the cyclical factor declines gradually with age, independent of gender and education. For less educated men and women (less than high school) there is also a pronounced step down for those aged 65 years and older.

We identify the trend unemployment rate of a group with the sum of that group's age and cohort effects. From the 1980s to the present trend unemployment rates tend to decline for younger workers and increase for older workers. With few exceptions we do not find large changes in group trends. The changes we do observe are mostly less than one percentage point. The exceptions are the most educated prime age women whose trend unemployment rate declines by about 2 percentage points, and the least educated younger (older) males whose trend unemployment rate decreases (increases) by about 1.5 percentage points. Across the different groups, age and cohort effects both contribute to trend changes with no apparent systematic pattern, except for the least and most educated prime age women where cohort effects seem to dominate.

In Table 3 we report changes in the groups' trend unemployment rates from 1979 to 2018. This exercise replicates the exercise from Section 2, Table 1, with a finer demographic grid and a more systematic removal of cyclical effects. The results from the two exercises are broadly consistent.

For men we find more increases than decreases in the trend unemployment rate across age and education groups. Most of the changes are small, less than one percentage point, except for the least educated males. For men with less than a high school education the trend rate declines for those between 25 and 44 years old, but increases for those 55 and older. Overall, age effects seem to account for more of the trend changes, but there is no clear pattern.

For women we find the opposite than for men. There are more age-education cells where the trend unemployment rate declines, but again for most groups the changes are small, except for the most educated prime age women. For women aged 25 to 55 years with a 
college education the trend unemployment rate declined by 1 to 2 percentage points. Also, unlike for men, cohort effects seem to account for more of the trend changes across women's age-education groups. This is especially true for the most educated prime age women and for women aged less than 25 years which we do not differentiate by education.

We illustrate the role of cohort and age effects in Figure 2 for the group of men with less than a high school education. The top five lines plot the age effects for our five age groups, and the bottom line plots the cohort effects. ${ }^{9}$ Clearly, age effects are not constant over time. There are short-run movements in the age effects such as the increase for 25-34 year old men during the 1980s recession, and there are medium-run swings such as the decline and then increase of the age effect for men 65 and older. The short-run swings in age effects suggest that our estimation method does not always extract the cycle for all demographic groups. ${ }^{10}$ The medium-run swings reflect, in part, changes in the relative trends of different age groups. Finally, there are also notable medium-run swings in cohort effects, but movements in the cohort effects tend to be small relative to movements in age effects. ${ }^{1112}$ The estimates of the age and cohort effects are not very precise. The dashed lines in Figure 2 represent two standard error bands based on the smoothed posterior variances of the unobserved states. Note that the changes of age and cohort effects over time usually stay within their initial error bands. These wide error bands are not specific to the group of men with less than a high school education but are common to all demographic groups.

The circles in Figure 2 illustrate how cohort and age effects interact in the determination of trend unemployment over the life-cycle of a group that enters in 1976. Relative to those that entered in 1960 this group has a permanently higher trend unemployment rate, about 1 percentage point. Over the next ten years their trend rate first increases and then declines with the 1980s recession. Once they turn 35 years old their trend unemployment rate declines, but it is still about 1 percentage point higher than it was for that age group at the time the cohort entered in 1976. At the time this cohort gets close to retirement their age effect is about the same as it was for that age group in 1976.

\footnotetext{
${ }^{9}$ We estimate age effects for the duration of our sample starting in 1976, and we can infer cohort effects for those entering the sample prior to 1976.

${ }^{10} \mathrm{We}$ are hesitant to interpret the apparent cyclical responses in age effects as persistent scarring of that particular age group. Scarring would be better reflected in a change to the cohort effect, but our estimation imposes a fixed cohort effect.

${ }^{11}$ We have estimated a constrained version of our model with fixed age and cohort effects, which is closer to the approach of Aaronson et al (2014) and Montes (2018). The fit of the constrained model is significantly worse, and the inferred cohort effects are extremely volatile.

${ }^{12}$ The fact that we observe medium-run swings in age and cohort effects makes us more comfortable with not including deterministic drift terms in the laws of motion for age and cohort effects.
} 


\subsection{LFP rates: cycle and trend}

We now turn to the results for the trend in the labor force participation rate. In the estimation, we decompose each groups' LFP rate into a cyclical component, and cohort and age components. The cyclical component is the groups' response to the estimated cyclical effect from the unemployment rate model. We call LFP rates pro-cyclical if they are negatively correlated with the cyclical effect, that is, the LFP rate increases as the cyclical unemployment rate declines.

In Table 4 we report the cyclical response of LFP rates for the different demographic groups. The response is the sum of the coefficients on the cyclical effect with corresponding standard deviations in parentheses. For almost all demographic groups the LFP rate is procyclical. Exceptions are men older than 65 with at least some college education, and women older than 55. The response coefficients tend to be small and not statistically significant, except for the 16-19 year old ones.

In Table 5 we report changes in the groups' trend LFP rates from 1979 to 2018. Like Table 3 for the group unemployment rates this exercise replicates the exercise from Section 2, Table 1, with a finer demographic grid and a more systematic removal of cyclical effects. Given the limited cyclical volatility of LFP rates it should not be surprising that the two exercises yield similar results.

The largest trend decline of LFP rates occurs for those 16-24 years old. In particular, for the very young the trend LFP declines by more than 20 percentage points, most of it due to cohort effects.

For men, the trend LFP rates decline for all age and education groups with the largest declines among those younger than 65 and with less than a college degree. For example, for those with a high school degree trend LFP rates decline by about 10 percentage points. LFP rates of men 65 and older or with a college degree decline by much less. For most groups the age effect is the largest contributor to the decline in trend LFP rates, but there are also a number of notable cohort effects among prime-age males with a high school or some college education.

For women the trend LFP rates increase for almost all age and education groups with the largest increases among those with more than a high school education. For example, for those with a college degree LFP rates increase between 8 and 16 percentage points. Relative to men, cohort effects are more often the largest contributor to the increase in trend LFP rates, especially for college educated women, but even for women age effects remain the main reason for trend changes in a large number of groups. Unlike for changes in trend unemployment rates, age and cohort effects mostly work in the same direction. 
Figure 3 shows the estimated cohort and age effects for women with a college education. Clearly, age effects are not constant over time: they first increase and then plateau or decrease for all age groups. Increasing cohort effects are important for women entering prior to the 1980s, but afterwards cohort effects are relatively stable. Unlike for unemployment rates, estimates of age and cohort effects for LFP rates are relatively precise. Based on the two standard deviation error bands, the dashed lines in Figure 3, the changes in age and cohort effects over time are significant. And these narrower error bands for estimated age and cohort effects of LFP rates are common to all demographic groups.

The circles in Figure 3 again illustrate how cohort and age effects interact in the determination of trend LFP over the life-cycle of a group that enters in 1976. Relative to those that entered in 1960 this group has a permanently higher trend LFP rate, about 7 percentage points. Over the next twenty years their trend rate increases noticeably, by about 10 percentage points. That is, when they turn 45 years old their trend LFP rate is about 10 percentage points higher than it was for that age group in 1976. As usual the LFP rate declines once this group reaches age 55 .

\section{$5 \quad$ Aggregate Unemployment and LFP Trend}

We use the groups' population shares and our estimates of the groups' trend unemployment and LFP rates to construct the trend for the aggregate unemployment and LFP rate. The relative contributions of group trend rates and demographic factors to the trends of the aggregate unemployment and LFP rate differ. On the one hand, trends in group LFP participation rates and changes in the demographic composition all make important contributions to the trend of the aggregate LFP rate. On the other hand, the trend for the aggregate unemployment rate is almost exclusively driven by demographic changes and not by changes in group trends for unemployment and LFP rates. Finally, the cyclical component of the aggregate LFP rate is substantially less volatile than the one of the aggregate unemployment rate, and the two cyclical components are negatively correlated.

We first discuss the aggregate LFP rate which is a simple population share weighted average of the group LFP rates, equation (2). The aggregate LFP rate increased from 1976 on, reaching its peak just prior to 2000, and declined thereafter; Figure 4. The actual LFP rate does not deviate much from trend, it tends to fall below trend in recessions and then stays below trend for most of the expansion. The exceptions are the expansions following the 1984 and 2007-09 recessions when the estimated LFP rate trend noticeably exceeded the actual values for an extended period of time. We estimate the 2018 trend LFP rate to be at 62.7 percent, about half a percentage point lower than the CBO (2018) estimate of the 
potential LFP rate in $2018 .^{13}$

We construct two counterfactuals to demonstrate how the trend of the aggregate LFP rate depends on changes in the trend LFP rates of demographic groups and the demographic composition of the population, Figure 4. For the first counterfactual, we fix the population shares by age, gender, and education at their 2000 values, and use our estimates of the LFP rate trends for each demographic group. The counterfactual retains the hump-shaped path, that is, it reflects the increasing trend for LFP rates of women prior to 2000, and the declining trend for LFP rates of young groups post-2000, but it peaks earlier, just before 1990.

Prior to 2000 the counterfactual exceeds the trend path which means that from 1976 to 2000 the population composition was changing towards groups with higher participation rates. The main driver of this process was increased educational attainment as we can see from a comparison with our second counterfactual. For this counterfactual we fix the educational distribution conditional on age and gender at its 2000 values, and we use the actual population shares by age and gender and the trend group LFP rates. This second counterfactual remains close to the first counterfactual, that is, changes in the age distribution alone have a minor impact on the trend aggregate LFP rate prior to 2000. Taking the actual population shares, that is, introducing the actual educational attainment of the population, then moves the second counterfactual to the trend. Thus increasing educational attainment is a major source for the increase of the aggregate LFP rate trend prior to 2000.

A similar comparison of the trend with the two counterfactuals for the post-2000 period shows that increased educational attainment counteracted much of the widely discussed impact of population ageing on the LFP rate. Whereas the ageing of the population contributes to an almost three percentage point decline of the trend LFP rate by 2018, the difference between the blue and green lines, the increased educational attainment eliminates two percentage points of this gap.

We now proceed to the aggregate unemployment rate which is a nonlinear function of population share weighted group unemployment and LFP rates, equation (3). Figure 5 displays the actual unemployment rate and our trend estimate. Despite the apparent stability of the trends in group unemployment rates we observe a noticeable monotonic decline of the trend in the aggregate unemployment rate: from $7 \%$ in 1976 to $4.6 \%$ in 2018 . Relative to

\footnotetext{
${ }^{13}$ In Appendix 8.1 we consider two alternative estimators of the trend LFP rate based on two measures for which we assume that we know the true cyclical effect. The measures consist of the smoothed posterior of the groups' cyclical unemployment effect and the groups' observed average unemployment rate. The results are very similar, and well within the two standard deviation error bands of about $+/-0.4$ ppts around our baseline trend.
} 
estimates of group trend unemployment rates, the uncertainty associated with the estimate of the aggregate trend unemployment rate is smaller. The two standard deviation error bands of the trend unemployment rate estimates from the beginning and end of sample do not overlap. We note that our estimates of the trend unemployment rate are in line with the CBO (2018) estimates of the natural rate at the end of the sample, but substantially higher at the beginning of the sample. ${ }^{14}$

Compared to the cyclicality of the LFP rate, the cyclical deviations of the unemployment rate from its trend are large. Given the decline in the trend unemployment rate, the deviation of the actual unemployment rate from its trend value following the 2007-09 recession is exceptional, even when compared to the early 1980s recession. By 2016 the unemployment rate has returned to trend, and in 2018 the unemployment rate is significantly below its trend.

In order to understand the relative contributions of changes in the trends of group unemployment and LFP rates and population shares to changes in the trend of the aggregate unemployment rate we construct three counterfactuals, Figure 5. For the first counterfactual we use our estimates of the groups' trend unemployment rates, and fix the groups' trend LFP rates and population shares for age, gender, and education, at their 2000 values. This counterfactual is quite stable for the sample period, that is, the limited changes in the groups' trend unemployment rates that we discussed in the previous section have only a small impact on the aggregate trend. For the second counterfactual, we replace the fixed trend LFP rates from 2000 in the first counterfactual with their estimated time path. Despite the large changes in the trends of group LFP rates this has only a limited impact on the trend of the aggregate unemployment rate. For the third counterfactual we use our estimates of the groups' trend unemployment and LFP rates together with the actual population shares by age and gender, but fix the distribution of educational attainment conditional on age and gender at its 2000 values. This third counterfactual starts out at $6.3 \%$ in 1976 and ends at $5 \%$ in 2017 , that is, the ageing of the population accounts for 1.3 percentage points or about half of the decline in the trend unemployment rate. The remaining part, the move from the third counterfactual to trend, then reflects the contribution from increased educational attainment of the population since 1976 and accounts for about two fifths of the decline in the trend unemployment rate. To summarize, the decline in the trend of the aggregate

\footnotetext{
${ }^{14}$ The CBO now uses two different methods to estimate the natural rate of unemployment, Shakleton (2018). For the period prior to 2005 the estimated natural rate of unemployment is based on a Philips curve, but starting in 2005, the natural rate of unemployment is calculated as a population weighted average of demographic group unemployment and LFP rates that are fixed at their 2005 values. The latter approach is similar to our construction of the trend unemployment rate.
} 
unemployment rate is mainly driven by demographic factors, about half of it attributable to the population getting older and most of the rest attributable to the population getting more educated. ${ }^{15}$

\section{Unemployment and LFP Rate Projections}

Given the role that demographic trends play in the determination of the trend in the aggregate LFP rate and unemployment rate, it seems reasonable to project the future path of these aggregate trends based on demographic projections. For this purpose we need population projections by age and gender, and projections of future educational attainment. We take the first projection from the CBO (2018) and we project future educational attainment based on an estimated simple cohort model for age-gender conditional education shares. Using our preferred model of educational attainment, we project that over the next ten years the trend LFP rate will decline another 1.6 ppts from its current value of 62.7 percent, and the trend unemployment rate will decline by 0.4 ppts from its current value of 4.7 percent.

Educational attainment is defined for those 25 years and older, and we model the behavior of age-gender contingent education shares, $\bar{w}_{e, g}$, that is, the fraction of an age-gender group $g$ that has education level $e$. We use the five age and four education groups consistent with our cohort models of unemployment and labor force participation. We assume that the education shares for age groups evolve according to a cohort model with no age effects

$$
\begin{aligned}
\bar{w}_{e, g, t} & =\frac{1}{\# A_{g}} \sum_{a \in A_{g}} w_{e, a, t}+\varepsilon_{e, g, t}^{\bar{w}} \text { with iid } \varepsilon_{e, g, t}^{\bar{w}} \sim N\left(0, \sigma_{\bar{w}, g}^{2}\right) \\
w_{e, 25, t} & =\delta_{e, 0}+w_{e, 25, t-1}+\varepsilon_{25, t}^{e} \text { with iid } \varepsilon_{e, 25, t}^{w} \sim N\left(0, \sigma_{e, 0}^{2}\right) \\
w_{e, a, t} & =\delta_{e, g}+w_{e, a-1, t-1}+\varepsilon_{e, a, t}^{w} \text { with iid } \varepsilon_{e, a . t}^{w} \sim N\left(0, \sigma_{e, 1}^{2}\right) \text { for } a \in A_{g} .
\end{aligned}
$$

For each education group we assume that there is an initial value for those who enter at age 25. The initial cohort effect of a new cohort is a random variation of the initial effect of the new cohort in the previous period. The measured education shares for age groups can change over time, possibly due to differential death rates across age groups, see, for example,

\footnotetext{
${ }^{15}$ Shimer (1998) has argued that changes in labor force shares of groups defined by education may affect the trend unemployment rates of these groups. Thus separating out the contributions coming from changes in trend unemployment rates from the changes in labor force shares may not be possible. Our decomposition of the trend unemployment rate suggests that this is not much of an issue. First, even with the large changes in education shares the estimated trend unemployment rates of these groups have not changed much. Second, as we show in Appendix 8.2 the long-run correlations between unemployment rates and labor force shares for groups defined by education are very small, mostly insignificantly different from zero.
} 
Aaronson and Sullivan (2001). The model is estimated separately for each gender-education group using maximum likelihood and the Kalman-filter. ${ }^{16}$

We estimate two versions of this model. First, we estimate the model with no deterministic drift, $\delta_{e, j}=0$. Figure 6 displays the smoothed posterior estimates of cohort effects at the time a cohort enters the sample and at the end of the sample or at the time the cohort exits the sample. It is apparent that the education shares display systematic drift: in a cohort the shares of those with more than a high-school education tend to increase over time and the shares with a high-school education or less tend to decrease over time. We therefore estimate the model allowing for non-zero drift terms, $\delta_{e, j} \neq 0$, which we use for our baseline projection. ${ }^{17}$

Table 6 shows how the trend projections for the aggregate LFP and unemployment rate depend on the assumptions made for the evolution of future educational attainment. The third column displays the impact of ageing, assuming that the age-contingent education shares remain at their 2018 values. For this assumption the trend LFP rate is predicted to decline by another 2.5 ppts over the next ten years. The first and second column show how predicted increases in educational attainment dampen some of that decline. The second column shows that taking into account the built in higher educational attainment in recent cohorts will cut that decline by about 0.4 ppts, even if cohort education shares remain fixed. The first column contains projections from our preferred baseline model. It shows that taking into account increasing educational attainment within cohorts will cut that decline by another 0.5 ppts. The fourth column shows that our baseline forecast predicts a smaller decline of the trend LFP rate over the next ten years than does the CBO (2018) forecast. As for the trend unemployment rate, our preferred baseline model predicts a further decline by 0.3 ppts, unlike the CBO natural rate which is forecast to remain unchanged. Taking into account the predicted increase in educational attainment increases the predicted decline over the next ten years.

\section{Conclusions}

We estimate trends for the LFP and unemployment rates of demographic groups defined by age, gender and education, and we use these trends, together with the groups' population shares, to construct the trends of the aggregate LFP and unemployment rate. We charac-

\footnotetext{
${ }^{16}$ For the projections we use the estimated models for those with a high school education or higher and define the education share for those with less than a high school education as the residual.

${ }^{17}$ Even though the estimates for the drift terms tend to be not significant, the drift terms capture the systematic movements in the education shares. The coefficient estimates are in Appendix 8.3, Table 7.
} 
terize a group's LFP and unemployment rate using a parsimonious statistical model of age, cohort, and cycle effects, and we define the trend as the sum of the age and cohort effects. In contrast to alternative approaches, our model of group-specific trends features time-varying age effects, which we estimate using standard data filtering techniques.

The estimated trend in the aggregate unemployment rate declines almost monotonically from $7 \%$ in 1976 to $4.7 \%$ in 2018 , and is almost exclusively driven by demographic factors with roughly equal contributions from an older and more educated population. The estimated trend in the aggregate LFP rate is hump-shaped with a peak in 2000. In contrast to the trend unemployment rate, the trend LFP rate is not only driven by demographics, with increasing educational attainment being important throughout the sample and ageing of the population becoming more important since 2000, but also by changes of groups' trend LFP rates, e.g., for women prior to 2000.

We construct ten year projections of the aggregate trends, using a cohort model of agegender contingent educational attainment. The cohort model predicts an increase in educational attainment in the next ten years. Combining Census Bureau population forecasts and our forecasts for educational attainment, we project that over the next 10 years the trend LFP rate will decline to $61.1 \%$ from its 2018 value of $62.7 \%$, and the trend unemployment rate will decline to $4.3 \%$ from its 2018 value of $4.7 \%$. 


\section{References}

[1] Aaronson, Daniel, and Daniel Sullivan. 2001. Growth in Worker Quality. Economic Perspectives, Federal Reserve Bank of Chicago, 2001 Q4.

[2] Aaronson, Stephanie, Tomaz Cajner, Bruce Fallick, Felix Galbis-Reig, Christopher Smith, and William Wascher. 2014. Labor Force Participation: Recent Developments and Future Prospects. Brookings Papers on Economic Activity, Vol. 2014: 197-275.

[3] Aaronson, Stephanie, Bruce Fallick, Andrew Figura, Jonathan Pingle, and William Wascher. 2006. The Recent Decline in the Labor Force Participation Rate and Its Implications for Potential Labor Supply. Brookings Papers on Economic Activity, Spring 2006, 69-134.

[4] Balleer, Almut, Ramón Gómez-Salvador, and Jarkko Turunen. 2009. Labor Force Participation in the Euro Area: a Cohort Based Analysis, European Central Bank, Working Paper Series, No. 1049.

[5] Barnichon, Regis, and Geert Mesters. 2018. On the Demographic Adjustment of Unemployment, The Review of Economics and Statistics, 100(2): 219-231.

[6] Congressional Budget Office. 2018. An Update to the Economic Outlook: 2018 to 2028. https://www.cbo.gov/publication/54318

[7] Bureau of the Census. 2018. Population Projections. https://www.census.gov/programs-surveys/popproj.html

[8] Cairó, Isabel, Shigeru Fujita, and Camilo Morales-Jiménez. 2019. Elasticities of Labor Supply and Labor Force Participation Flows. FRB Philadelphia Working Paper 19-03.

[9] Daly, Mary C., Osborne Jackson, and Robert G. Valetta. 2007. Educational Attainment, Unemployment, and Wage Inflation. FRBSF Economic Review 49-61.

[10] Elsby, M., Hobijn, B. A. Sahin. 2010. The Labor Market in the Great Recession. Brooking Panel on Economic Activity, April 2010

[11] Kudlyak, Marianna. 2013. A Cohort Model of Labor Force Participation, Federal Reserve Bank of Richmond Economic Quarterly 99(1): 25-43.

[12] Montes, Joshua. 2018. CBO's Projection of Labor Force Participation Rates, Congressional Budget Office, Working Paper 2018-04. 
[13] Müller, Ullrich, and Mark Watson. 2018. Long-Run Covariability. Econometrica 86, 775-804.

[14] Shackleton, Robert. 2018. Estimating and Projecting Potential Output Using CBO's Forecasting Growth Model. CBO Working Paper 2018-03. https://www.cbo.gov/publication/53558

[15] Shimer, Robert. 1998. Why Is the U.S. Unemployment Rate so Much Lower? NBER Macroeconomics Annual, vol. 13, 1998, pp. 11-61.

[16] Tuzemen, Didem, and Willem Van Zandweghe. 2018. The Cyclical Behavior of Labor Force Participation. FRB Kansas City Working Paper No. 18-08. 


\section{Appendix}

\subsection{Cyclical effects for the LFP rate}

The state space model for a demographic group's LFP rate is characterized by the measurement equations

$$
\begin{aligned}
\bar{q}_{g, t} & =\frac{1}{\# A_{g}} \sum_{a \in A_{g}} x_{a, t}+\bar{y}_{g, t}+\gamma_{g} \sum_{s=0}^{n} \rho_{s} z_{t-s}+\varepsilon_{g, t}^{\bar{q}} \text { with iid } \varepsilon_{g, t}^{\bar{q}} \sim N\left(0, \sigma_{g, \bar{q}}^{2}\right) \\
\tilde{z}_{t} & =z_{t}+\varepsilon_{t}^{\tilde{z}} \text { with iid } \varepsilon_{t}^{\tilde{z}} \sim N\left(0, \sigma_{\tilde{z}}^{2}\right),
\end{aligned}
$$

where $\tilde{z}$ is a noisy signal of the cyclical effect, and the state transition equations

$$
\begin{aligned}
x_{1, t} & =x_{1, t-1}+\varepsilon_{1 t}^{x} \text { with iid } \varepsilon_{1 t}^{x} \sim N\left(0, \sigma_{1 x}^{2}\right) \\
x_{a, t} & =x_{a-1, t-1} \text { for } a>1 \\
\bar{y}_{g, t} & =\bar{y}_{g, t-1}+\varepsilon_{g, t}^{\bar{y}} \text { with iid } \varepsilon_{g, t}^{\bar{y}} \sim N\left(0, \sigma_{g \bar{y}}^{2}\right) \text { for } g \geq 1, \\
z_{t} & =\rho z_{t-1}+\varepsilon_{t}^{z} \text { with iid } \varepsilon_{t}^{z} \sim N\left(0, \sigma_{z}^{2}\right)
\end{aligned}
$$

We estimate the parameters $\left(\sigma_{g, \bar{q}}^{2}, \sigma_{1 x}^{2}, \sigma_{g \bar{y}}^{2}, \gamma_{g}\right)$ and take the estimated parameters for the cyclical effect $\left(\rho, \sigma_{z}^{2}\right)$ from the group's unemployment rate model as given. Furthermore, the nosiy signal for the cyclical effect is the smoothed posterior estimate for the group's cyclical unemployment effect, and we take the average variance of the smoothed posterior as the variance of the noise term $\sigma_{\tilde{z}}^{2}$.

As a robustness check we consider two alternative models of the cyclical effect for the labor force participation rates. The implied estimates for the aggregate LFP rate are displayed in Figure 7. The first alternative assumes that the smoothed posterior mean estimate of the group's cyclical unemployment effect represents the true cyclical effect without noise. The implied trend for the aggregate LFP rate is almost the same as for our baseline estimate, but unsurprisingly the standard error band is smaller. For the second alternative we note that the groups' average unemployment rates are highly correlated with our estimated cyclical effects for the groups' unemployment rates. We therefore take the groups' average unemployment rates as the observed true cyclical effect for the groups' labor force participation rates. The LFP rate trend implied by this alternative model tends to be close to the trend of the baseline model, but is slightly higher than the baseline trend for the most recent years. 


\subsection{Long-run correlation of unemployment rate and labor force shares}

Shimer (1998) argues that in the long run the unemployment rates of demographic groups may be correlated with the labor force shares of these groups. If this is correct then decomposing changes in the aggregate trend unemployment rate into changes coming from group trend unemployment rates and changes coming from the labor force shares of the groups are a pure accounting exercise and should not be interpreted as causal. He argues that this is especially true for groups defined by education decomposition. For example, if employers care about relative education or education is contaminated by unobserved quality then changes in education shares can affect education contingent unemployment. In the end this is an empirical issue, and Daly, Jackson, and Valetta (2007) argue that there is no correlation between unemployment rates and labor force shares for groups defined by age, gender, and education.

We extend the analysis of Daly et al (2007) for our sample and calculate the long run correlations between unemployment rates and labor force shares using the approach of Müller and Watson (2018). In Figure 8 we plot the posterior medians, and $67 \%$ and $90 \%$ confidence intervals for the long run correlation between unemployment rates and labor force shares for demographic groups defined by education, age, and gender. Most of the median correlations are close to zero, and there is no group for which zero is not included in the $90 \%$ confidence interval.

\subsection{A cohort model for education}

Figure 9 illustrates the role of different assumptions on the dynamics of education shares for medium term projections of these shares. Here we plot the actual and predicted shares of male high-school (HS) graduates for the five age groups using our two models for the evolution of education shares, together with the simple assumption that the education shares of agegender groups remain fixed at their last observed values. Clearly the predictions are quite different. The evolution of education shares in the model without drift can be understood as follows. Since prior to 2018 the HS share among the 25-34 year olds was increasing, the HS share of entering cohorts must have been increasing. Since the forecast applies the share of the last cohort that entered to all future entering cohorts, the average share of the age group is forecast to increase. Since prior to 2018 the HS share of the 35-44 year olds was lower than that for the 25-34 year olds, and going forward the cohorts in the 35-44 year olds are being replaced with cohorts from the 25-34 year olds, the average share of the age group 35-44 is forecast to increase. By an analogous argument the average HS share of the 45-54 
year olds is decreasing since prior to 2018 that group's HS was higher than for the 35-44 year olds. And similar arguments apply to the remaining age groups. Allowing for non-zero drift in the education shares can amplify (25-34, 45-54, 55-64), dampen (65-79), or completely reverse (35-44) these patterns. 
Table 1: Unemployment, Labor Force Participation, and Demographics (1)

(2)

(3)

(4)

Men, 25-54 Men, 55+ Women, 25-54 Women, 55+

(A) Unemployment Rate

1979

\begin{tabular}{|c|c|c|c|c|}
\hline HS or less & 4.4 & 3.4 & 6.4 & 3.4 \\
\hline More than HS & 2.1 & 2.1 & 3.9 & 2.8 \\
\hline & \multicolumn{4}{|c|}{2018} \\
\hline HS or less & 4.5 & 4.1 & 5.5 & 3.2 \\
\hline \multirow[t]{3}{*}{ More than HS } & 2.5 & 2.7 & 2.8 & 3.2 \\
\hline & \multicolumn{4}{|c|}{ (B) LFP Rate } \\
\hline & \multicolumn{4}{|c|}{1979} \\
\hline HS or less & 93.0 & 42.9 & 58.6 & 21.7 \\
\hline \multirow[t]{2}{*}{ More than HS } & 96.4 & 60.5 & 70.3 & 30.7 \\
\hline & \multicolumn{4}{|c|}{2018} \\
\hline HS or less & 84.3 & 40.3 & 63.3 & 25.9 \\
\hline \multirow[t]{3}{*}{ More than HS } & 92.1 & 50.3 & 80.6 & 41.7 \\
\hline & \multicolumn{4}{|c|}{ (C) Population Shares } \\
\hline & \multicolumn{4}{|c|}{1979} \\
\hline HS or less & 18.1 & 12.0 & 22.5 & 16.2 \\
\hline \multirow[t]{2}{*}{ More than HS } & 13.3 & 3.4 & 11.0 & 3.5 \\
\hline & \multicolumn{4}{|c|}{2018} \\
\hline HS or less & 11.1 & 8.2 & 9.2 & 10.1 \\
\hline More than HS & 17.3 & 11.5 & 19.9 & 12.8 \\
\hline
\end{tabular}

Note: Table shows data for 1979 and 2018, years with unemployment troughs at the beginning and end of sample; population 25 years and older. 
Table 2: Cyclical Response of Unemployment Rates

\begin{tabular}{lrrrrr}
\hline & $(1)$ & $(2)$ & $(3)$ & $(4)$ & $(5)$ \\
& All & $<$ HS & HS & $<$ COL & COL + \\
\hline \multirow{3}{*}{$20-24$} & & & Male & & \\
& 0.75 & & & & \\
& $(0.04)$ & & & & \\
$35-44$ & & 0.91 & 0.75 & 0.80 & 0.95 \\
& & $(0.06)$ & $(0.04)$ & $(0.04)$ & $(0.08)$ \\
$45-54$ & & 0.82 & 0.67 & 0.81 & 0.95 \\
& & $(0.06)$ & $(0.04)$ & $(0.04)$ & $(0.08)$ \\
$55-64$ & & 0.69 & 0.64 & 0.73 & 0.91 \\
& & $(0.05)$ & $(0.04)$ & $(0.04)$ & $(0.10)$ \\
$65+$ & & 0.28 & 0.33 & 0.61 & 0.74 \\
& & $(0.06)$ & $(0.04)$ & $(0.08)$ & $(0.13)$ \\
\hline \multirow{5}{*}{$20-24$} & 0.66 & & Female & & \\
& $(0.03)$ & & & & \\
$35-44$ & & 0.85 & 0.77 & 0.77 & 0.91 \\
& & $(0.07)$ & $(0.05)$ & $(0.04)$ & $(0.08)$ \\
$45-54$ & & 0.73 & 0.65 & 0.70 & 0.88 \\
& & $(0.06)$ & $(0.04)$ & $(0.05)$ & $(0.08)$ \\
$55-64$ & & 0.48 & 0.60 & 0.73 & 0.85 \\
& & $(0.05)$ & $(0.04)$ & $(0.06)$ & $(0.09)$ \\
$65+$ & 0.27 & 0.43 & 0.72 & 0.73 \\
& & $(0.05)$ & $(0.06)$ & $(0.08)$ & $(0.13)$ \\
\hline \hline
\end{tabular}

Note: The age groups 16-24 are not differentiated by education. The cyclical response of age groups 16-19 and 25-34 is normalized to one. Standard deviations in parenthesis. 
Table 3: Change of Trend Unemployment Rates from 1979 to 2018

\begin{tabular}{|c|c|c|c|c|c|}
\hline & (1) & $(2)$ & (3) & (4) & (5) \\
\hline & All & $<\mathrm{HS}$ & HS & $<\mathrm{COL}$ & $\mathrm{COL}+$ \\
\hline & & & Male & & \\
\hline \multirow[t]{2}{*}{$16-19$} & 0.1 & & & & \\
\hline & $(-0.0,0.1)$ & & & & \\
\hline \multirow[t]{2}{*}{$20-24$} & -0.0 & & & & \\
\hline & $(0.0,-0.0)$ & & & & \\
\hline \multirow[t]{2}{*}{$25-34$} & & -1.8 & -0.3 & -0.7 & -0.5 \\
\hline & & $(-0.9,-0.8)$ & $(-0.0,-0.3)$ & $(-0.4,-0.3)$ & $(-0.0,-0.5)$ \\
\hline \multirow[t]{2}{*}{$35-44$} & & -0.8 & 0.4 & 0.2 & -0.1 \\
\hline & & $(-0.7,-0.1)$ & $(-0.0,0.4)$ & $(-0.3,0.5)$ & $(-0.0,-0.1)$ \\
\hline \multirow[t]{2}{*}{$45-54$} & & 0.5 & 0.5 & 0.0 & 0.4 \\
\hline & & $(-0.1,0.6)$ & $(0.0,0.5)$ & $(-0.3,0.3)$ & $(-0.0,0.4)$ \\
\hline \multirow[t]{2}{*}{$55-64$} & & 1.6 & 0.6 & 0.2 & 0.6 \\
\hline & & $(0.6,1.0)$ & $(0.0,0.6)$ & $(-0.0,0.2)$ & $(0.0,0.6)$ \\
\hline \multirow[t]{3}{*}{$65-79$} & & 1.4 & 0.4 & 0.1 & 0.8 \\
\hline & & $(0.5,0.9)$ & $(0.0,0.4)$ & $(0.3,-0.1)$ & $(0.0,0.8)$ \\
\hline & & & Female & & \\
\hline \multirow[t]{2}{*}{$16-19$} & -0.6 & & & & \\
\hline & $(-0.7,0.1)$ & & & & \\
\hline \multirow[t]{2}{*}{$20-24$} & -0.9 & & & & \\
\hline & $(-0.8,-0.2)$ & & & & \\
\hline \multirow[t]{2}{*}{$25-34$} & & -1.0 & -0.4 & -1.0 & -2.2 \\
\hline & & $(-0.9,-0.1)$ & $(-0.0,-0.4)$ & $(-0.1,-0.8)$ & $(-1.6,-0.5)$ \\
\hline \multirow[t]{2}{*}{$35-44$} & & -0.6 & 0.3 & -0.0 & -1.7 \\
\hline & & $(-0.9,0.3)$ & $(-0.0,0.3)$ & $(-0.1,0.1)$ & $(-1.5,-0.2)$ \\
\hline \multirow[t]{2}{*}{$45-54$} & & 0.0 & 0.1 & -0.2 & -0.7 \\
\hline & & $(0.1,-0.1)$ & $(-0.0,0.1)$ & $(-0.1,-0.2)$ & $(-0.9,0.2)$ \\
\hline \multirow[t]{2}{*}{$55-64$} & & 0.6 & 0.1 & 0.3 & 0.3 \\
\hline & & $(1.1,-0.5)$ & $(0.0,0.1)$ & $(-0.0,0.4)$ & $(-0.3,0.6)$ \\
\hline \multirow[t]{2}{*}{$65-79$} & & 1.2 & 0.2 & 0.9 & 0.3 \\
\hline & & $(0.6,0.6)$ & $(0.0,0.2)$ & $(0.0,0.9)$ & $(0.2,0.1)$ \\
\hline
\end{tabular}

Note: For each demographic group we calculate the percentage point change in the trend unemployment rate from 1979 to 2018. The first (second) number in parentheses denotes the contribution from the cohort (age) effect. The age groups 16-24 are not differentiated by education. The sample p\&4iod is 1976-2018. 
Table 4: Cyclical Response of LFP Rates

\begin{tabular}{|c|c|c|c|c|c|}
\hline & (1) & $(2)$ & (3) & $(4)$ & (5) \\
\hline & $16-24$ & $<\mathrm{HS}$ & $\mathrm{HS}$ & $<\mathrm{COL}$ & $\mathrm{COL}+$ \\
\hline & & & Male & & \\
\hline \multirow[t]{2}{*}{ Sum of CE } & -0.55 & -0.18 & -0.29 & -0.30 & -0.66 \\
\hline & $(0.11)$ & $(0.10)$ & $(0.09)$ & $(0.12)$ & $(0.27)$ \\
\hline \multirow[t]{2}{*}{$20-24$} & 0.43 & & & & \\
\hline & $(0.16)$ & & & & \\
\hline \multirow[t]{2}{*}{$35-44$} & & 0.98 & 0.54 & 0.49 & 0.18 \\
\hline & & $(0.72)$ & $(0.40)$ & $(0.38)$ & $(0.31)$ \\
\hline \multirow[t]{2}{*}{$45-54$} & & 1.65 & 0.68 & 1.04 & 0.41 \\
\hline & & $(0.91)$ & $(0.44)$ & $(0.55)$ & $(0.33)$ \\
\hline \multirow[t]{2}{*}{$55-64$} & & 1.69 & 2.00 & 1.32 & 0.05 \\
\hline & & $(0.96)$ & $(0.69)$ & $(0.67)$ & $(0.50)$ \\
\hline \multirow[t]{3}{*}{$65-79$} & & 0.07 & 0.56 & -0.32 & -1.00 \\
\hline & & $(0.42)$ & $(0.43)$ & $(0.47)$ & $(0.66)$ \\
\hline & \multicolumn{5}{|c|}{ Female } \\
\hline \multirow[t]{2}{*}{ Sum of CE } & -0.58 & -0.41 & -0.33 & -0.46 & -0.01 \\
\hline & $(0.13)$ & $(0.13)$ & $(0.14)$ & $(0.23)$ & $(0.20)$ \\
\hline \multirow[t]{2}{*}{$20-24$} & 0.32 & & & & \\
\hline & $(0.16)$ & & & & \\
\hline \multirow[t]{2}{*}{$35-44$} & & 0.58 & 0.61 & 0.73 & -0.35 \\
\hline & & $(0.35)$ & $(0.30)$ & $(0.58)$ & $(1.35)$ \\
\hline \multirow[t]{2}{*}{$45-54$} & & 0.61 & 0.40 & 0.35 & 1.53 \\
\hline & & $(0.30)$ & $(0.29)$ & $(0.60)$ & $(2.89)$ \\
\hline \multirow[t]{2}{*}{$55-64$} & & 0.32 & 0.86 & -0.31 & -1.00 \\
\hline & & $(0.28)$ & $(0.35)$ & $(0.52)$ & $(3.70)$ \\
\hline \multirow[t]{2}{*}{$65-79$} & & 0.10 & 0.14 & -0.39 & 1.98 \\
\hline & & $(0.20)$ & $(0.25)$ & $(0.49)$ & $(4.30)$ \\
\hline
\end{tabular}

Note: For each demographic group we take the estimated cyclical effect (CE) from the cohort model of the unemployment rate of that group as a noisy signal of the underlying CE. The response is proportional to the weighted sum of the current and two lags of the CE. The first row displays the sum of the coefficients on the CE with corresponding standard deviations in parenthesis. The remaining rows display the response coefficients of the different age groups in a demographic group. The response of the youngest group in each demographic group is normalized to one. The age group 16-24 is not differentiated by education. Thye sample period is 1976-2018. 
Table 5: Change of Trend LFP Rate from 1979 to 2018

\begin{tabular}{|c|c|c|c|c|c|}
\hline & (1) & (2) & (3) & (4) & (5) \\
\hline & $16-24$ & $<\mathrm{HS}$ & HS & $<\mathrm{COL}$ & $\mathrm{COL}+$ \\
\hline & & & Male & & \\
\hline \multirow[t]{2}{*}{$16-19$} & -28.4 & & & & \\
\hline & $(-19.2,-9.2)$ & & & & \\
\hline \multirow[t]{2}{*}{$20-24$} & -13.3 & & & & \\
\hline & $(-16.5,3.2)$ & & & & \\
\hline \multirow[t]{2}{*}{$25-34$} & & -10.0 & -9.3 & -5.8 & -2.7 \\
\hline & & $(-1.9,-8.2)$ & $(-6.1,-3.3)$ & $(-3.7,-2.1)$ & $(-0.0,-2.7)$ \\
\hline \multirow[t]{2}{*}{$35-44$} & & -6.1 & -9.1 & -5.9 & -2.5 \\
\hline & & $(-1.3,-4.8)$ & $(-5.4,-3.6)$ & $(-3.2,-2.7)$ & $(-0.0,-2.5)$ \\
\hline \multirow[t]{2}{*}{$45-54$} & & -10.1 & -9.9 & -6.5 & -3.1 \\
\hline & & $(-1.6,-8.5)$ & $(-3.9,-6.1)$ & $(-1.9,-4.7)$ & $(-0.0,-3.1)$ \\
\hline \multirow[t]{2}{*}{$55-64$} & & -6.6 & -9.0 & -8.2 & -4.0 \\
\hline & & $(-2.3,-4.3)$ & $(-2.3,-6.7)$ & $(-1.1,-7.1)$ & $(-0.0,-4.0)$ \\
\hline \multirow[t]{3}{*}{$65-79$} & & -1.0 & -4.6 & -2.1 & -1.8 \\
\hline & & $(-1.7,0.6)$ & $(-1.3,-3.3)$ & $(-0.4,-1.7)$ & $(0.0,-1.8)$ \\
\hline & & & Female & & \\
\hline \multirow[t]{2}{*}{$16-19$} & -21.2 & & & & \\
\hline & $(-9.7,-11.4)$ & & & & \\
\hline \multirow[t]{2}{*}{$20-24$} & -1.2 & & & & \\
\hline & $(-6.6,5.5)$ & & & & \\
\hline \multirow[t]{2}{*}{$25-34$} & & 0.9 & 4.2 & 9.0 & 8.3 \\
\hline & & $(-1.2,2.1)$ & $(-5.4,9.5)$ & $(-0.8,9.8)$ & $(1.6,6.6)$ \\
\hline \multirow[t]{2}{*}{$35-44$} & & -0.6 & 1.6 & 9.5 & 10.5 \\
\hline & & $(1.0,-1.6)$ & $(-0.1,1.6)$ & $(3.8,5.7)$ & $(5.1,5.4)$ \\
\hline \multirow[t]{2}{*}{$45-54$} & & 4.0 & 7.2 & 13.8 & 11.2 \\
\hline & & $(2.5,1.5)$ & $(6.0,1.2)$ & $(8.0,5.8)$ & $(7.8,3.5)$ \\
\hline \multirow[t]{2}{*}{$55-64$} & & 2.8 & 8.2 & 11.9 & 16.0 \\
\hline & & $(2.2,0.6)$ & $(7.4,0.8)$ & $(8.5,3.4)$ & $(8.3,7.7)$ \\
\hline \multirow[t]{2}{*}{$65-79$} & & 0.9 & 1.2 & 5.9 & 11.8 \\
\hline & & $(1.0,-0.1)$ & $(3.7,-2.5)$ & $(4.8,1.1)$ & $(5.1,6.7)$ \\
\hline
\end{tabular}

Note: For each demographic group we calculate the percentage point change in the trend unemployment rate from 1979 to 2018. The first (second) number in parentheses denotes the contribution from the cohort (age) effect. The age groups 16-24 are not differentiated by education. 
Table 6: The LFP and Unemployment Rate Trend Projections, 2019-2028

(1) (2) (3) (4)

Education forecasted, Education forecasted, Education fixed CBO (2018)

\begin{tabular}{ccccc} 
& model with drift & model with no drift & at 2018 & projections \\
\hline & \multicolumn{4}{c}{ LFP Rate Trend } \\
2018 & 62.7 & 62.7 & 62.7 & 63.1 \\
2019 & 62.5 & 62.4 & 62.4 & 62.9 \\
2020 & 62.3 & 62.2 & 62.1 & 62.8 \\
2021 & 62.1 & 62.0 & 61.8 & 62.6 \\
2022 & 61.9 & 61.8 & 61.6 & 62.4 \\
2023 & 61.8 & 61.5 & 61.3 & 62.2 \\
2024 & 61.6 & 61.3 & 61.1 & 61.9 \\
2025 & 61.5 & 61.1 & 60.8 & 61.7 \\
2026 & 61.3 & 60.9 & 60.6 & 61.5 \\
2027 & 61.2 & 60.8 & 60.4 & 61.3 \\
2028 & 61.1 & 60.6 & 60.2 & 61.1 \\
\hline
\end{tabular}

\begin{tabular}{llcll}
\hline \multicolumn{5}{c}{ Unemployment Rate Trend } \\
2018 & 4.7 & 4.7 & 4.7 & 4.6 \\
2019 & 4.6 & 4.6 & 4.6 & 4.6 \\
2020 & 4.6 & 4.6 & 4.6 & 4.6 \\
2021 & 4.5 & 4.6 & 4.6 & 4.6 \\
2022 & 4.5 & 4.6 & 4.6 & 4.6 \\
2023 & 4.5 & 4.5 & 4.6 & 4.6 \\
2024 & 4.4 & 4.5 & 4.6 & 4.6 \\
2025 & 4.4 & 4.5 & 4.6 & 4.6 \\
2026 & 4.4 & 4.5 & 4.5 & 4.6 \\
2027 & 4.3 & 4.5 & 4.5 & 4.6 \\
2028 & 4.3 & 4.4 & 4.5 & 4.6 \\
\hline \hline
\end{tabular}

Note: All projections of the aggregate LFP and unemployment rate use the CBO medium-fertility projections for the population size of age-gender groups. We project education shares of age-gender groups using (1) the cohort model with non-zero drift, (2) the cohort model with no drift, and (3) the fixed 2018 education shares. The fourth column represents the CBO (2018) projections for the potential LFP rate and the long-run natural rate of unemployment. 
Table 7: EducAtion Share Drifts

\begin{tabular}{|c|c|c|c|c|}
\hline & (1) & (2) & (3) & (4) \\
\hline & $<\mathrm{HS}$ & HS & $<\mathrm{COL}$ & $\mathrm{COL}+$ \\
\hline & \multicolumn{4}{|c|}{ Male } \\
\hline \multirow[t]{2}{*}{ Age 25} & -0.21 & -0.17 & 0.06 & 0.34 \\
\hline & $(0.18)$ & $(0.27)$ & $(0.28)$ & $(0.22)$ \\
\hline \multirow[t]{2}{*}{ Age 26-34 } & -0.71 & 0.66 & 0.15 & 0.34 \\
\hline & $(0.56)$ & $(0.85)$ & (1.06) & $(0.65)$ \\
\hline \multirow[t]{2}{*}{ Age $35-44$} & 0.25 & -1.13 & -0.06 & 0.57 \\
\hline & $(0.46)$ & $(0.70)$ & $(0.86)$ & $(0.53)$ \\
\hline \multirow[t]{2}{*}{ Age $45-54$} & -0.48 & 0.56 & 0.28 & -0.06 \\
\hline & $(0.37)$ & $(0.56)$ & $(0.69)$ & $(0.43)$ \\
\hline \multirow[t]{2}{*}{ Age 55-64 } & 0.11 & -0.66 & -0.03 & 0.33 \\
\hline & $(0.30)$ & $(0.46)$ & $(0.56)$ & $(0.35)$ \\
\hline \multirow[t]{3}{*}{ Age $65-79$} & -0.22 & 0.14 & 0.17 & 0.06 \\
\hline & $(0.16)$ & $(0.25)$ & $(0.31)$ & $(0.19)$ \\
\hline & \multicolumn{4}{|c|}{ Female } \\
\hline \multirow[t]{2}{*}{ Age 25} & -0.20 & -0.50 & 0.04 & 0.69 \\
\hline & $(0.06)$ & $(0.28)$ & $(0.39)$ & $(0.24)$ \\
\hline \multirow[t]{2}{*}{ Age 26-34 } & -0.26 & -0.17 & 0.11 & 0.69 \\
\hline & $(0.31)$ & (1.01) & $(1.30)$ & $(0.62)$ \\
\hline \multirow[t]{2}{*}{ Age $35-44$} & -0.14 & -0.63 & 0.17 & 0.30 \\
\hline & $(0.25)$ & $(0.82)$ & $(1.05)$ & $(0.51)$ \\
\hline \multirow[t]{2}{*}{ Age $45-54$} & -0.20 & -0.04 & 0.12 & 0.36 \\
\hline & $(0.20)$ & $(0.66)$ & $(0.85)$ & $(0.41)$ \\
\hline \multirow[t]{2}{*}{ Age 55-64 } & -0.01 & -0.37 & 0.16 & 0.02 \\
\hline & $(0.17)$ & $(0.54)$ & $(0.69)$ & $(0.33)$ \\
\hline \multirow[t]{2}{*}{ Age $65-79$} & 0.06 & -0.13 & 0.06 & 0.11 \\
\hline & $(0.09)$ & $(0.30)$ & $(0.38)$ & $(0.18)$ \\
\hline
\end{tabular}

Note: The drift terms $\delta$ are estimated for the entering cohort at age 25 and for the age groups of continuing cohorts. The coefficients are defined with respect to percentage shares, with standard deviations in parenthesis. 
Figure 1: Common Unemployment Cycle by Demographic Group
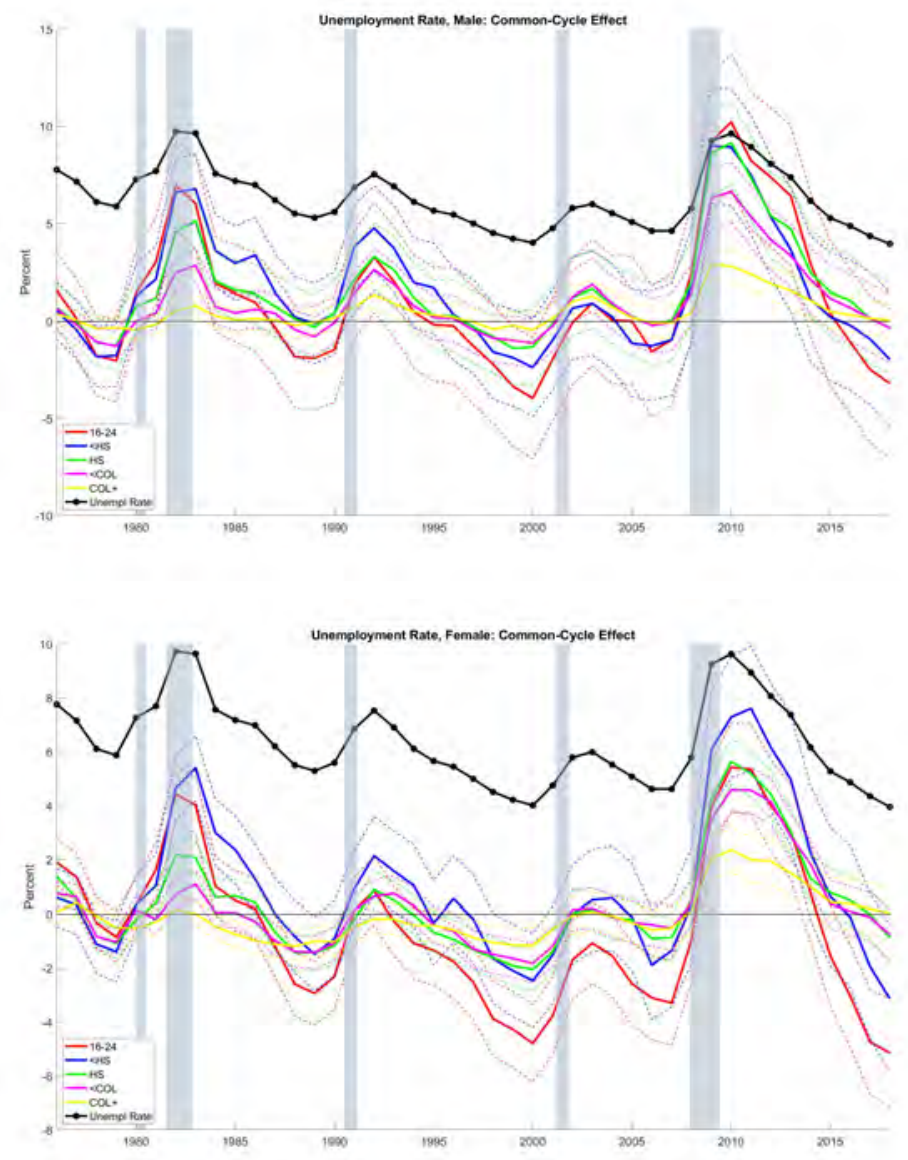

Note: Estimated cyclical effect for the age group 16-24 years old (not differentiated by education) and the demographic groups defined by gender and education. Dashed lines denote two standard error bands. The black line with circles is the aggregate unemployment rate. 
Figure 2: Cohort and Age Effects for Unemployment Rate of Males with Less Than High School Education

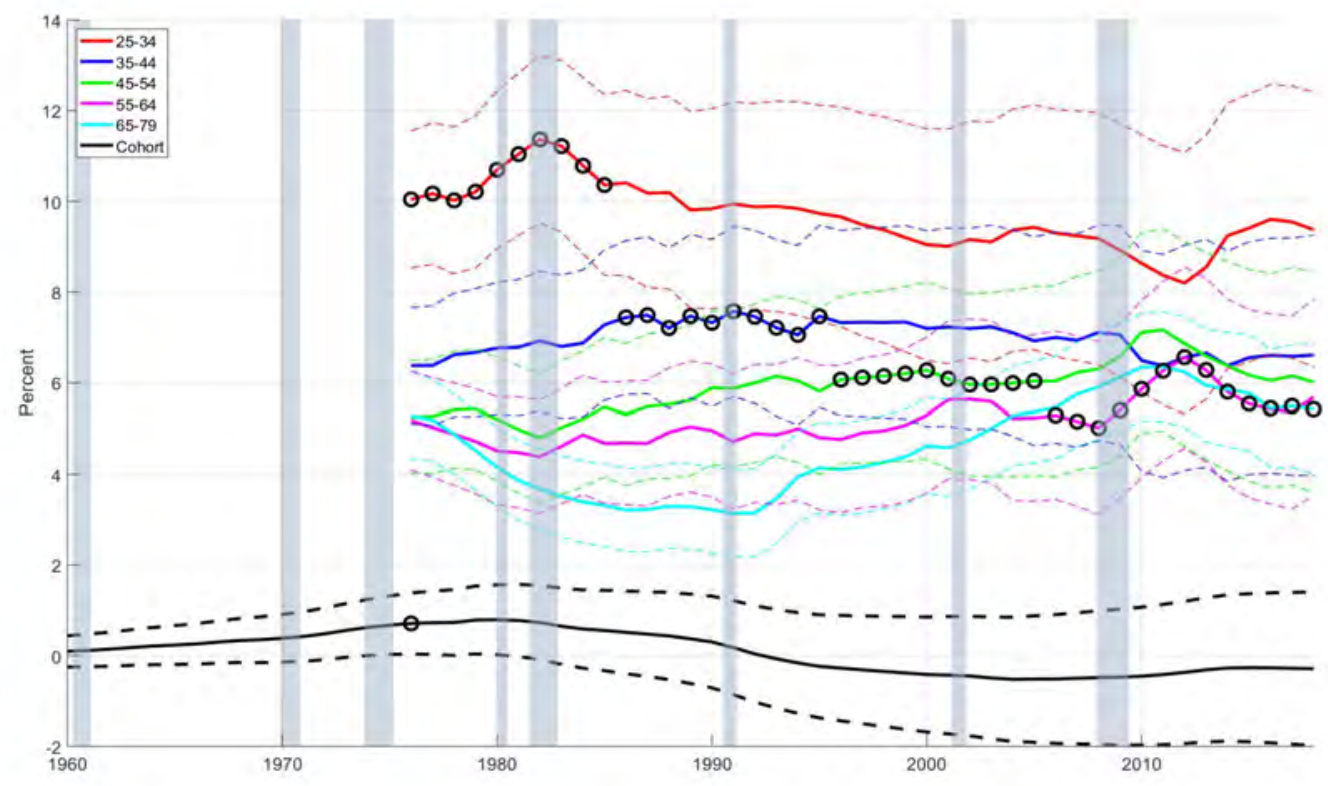

Note: Estimated cohort and age effects for groups aged 25-79 years. The circles mark the life cycle of a group that enters in 1976. Dashed lines denote two standard error bounds based on the smoothed posterior estimates from the Kalman filter. 
Figure 3: Cohort and Age Effects for LFP Rate of Females with College EDUCATION

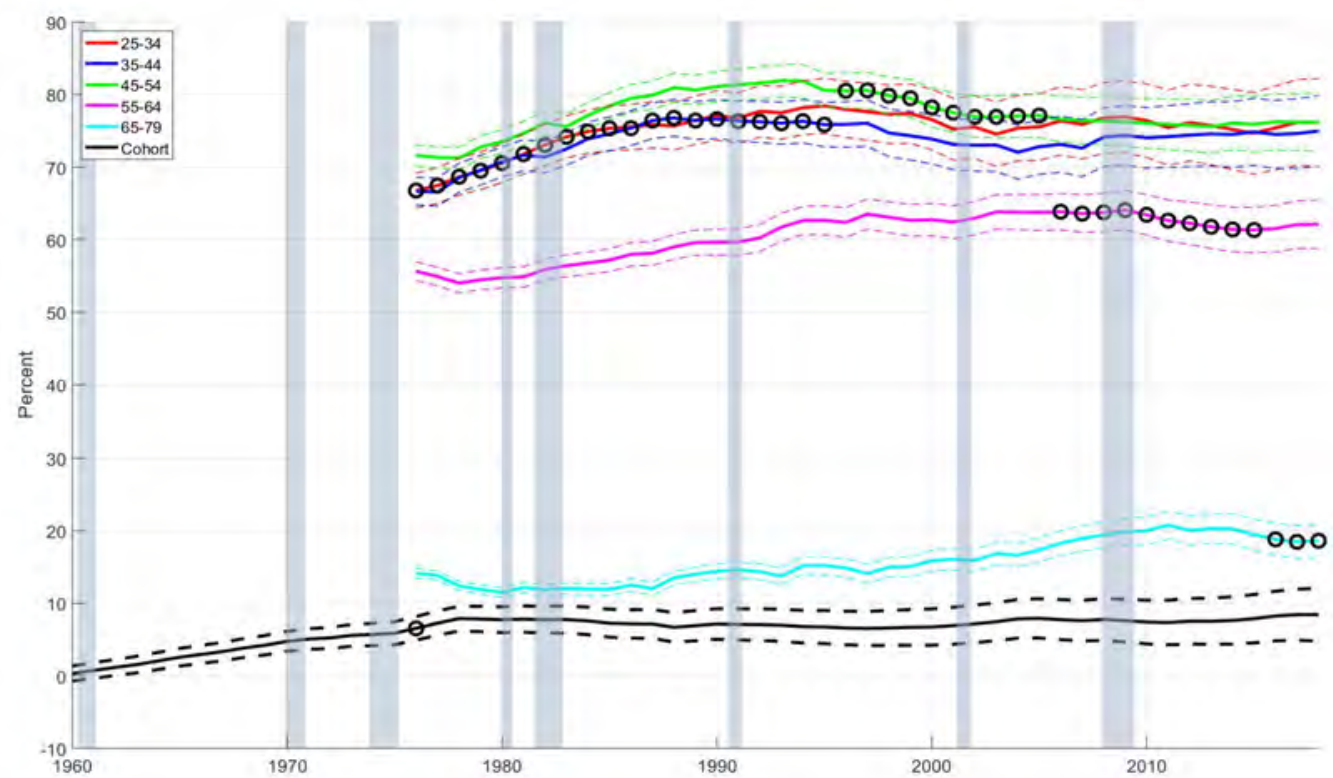

Note: Estimated cohort and age effects for groups aged 25-79 years. The circles mark the life cycle of a group that enters in 1976. Dashed lines denote two standard error bounds based on the smoothed posterior estimates from the Kalman filter. 


\section{Figure 4: Labor Force Participation Rate Trend}

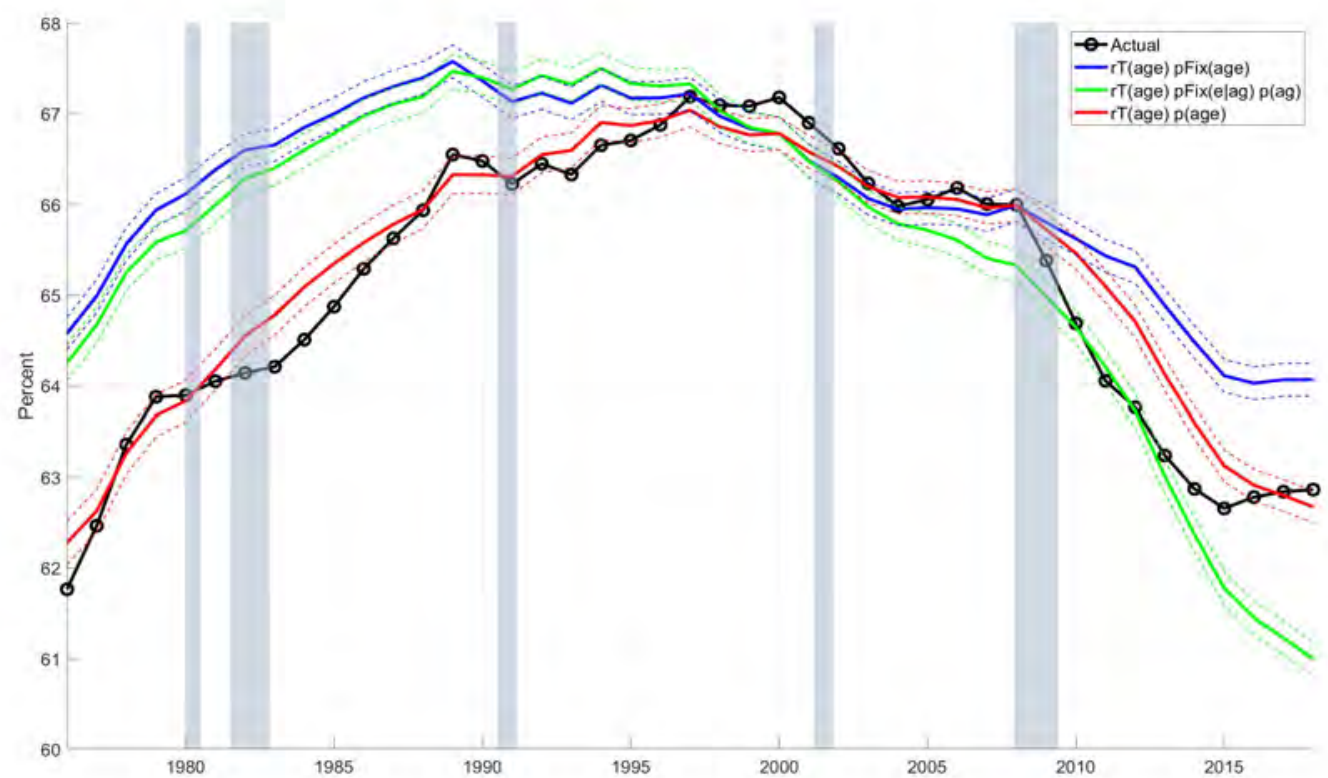

Note: The red line shows the estimated trend in the aggregate LFP rate. The blue line fixes the population distribution by age, gender, and education at its 2000 values and allows for variation of the LFP rate trend of each demographic group. The green line fixes the education distribution conditional on age and gender at its 2000 values and allows for variation of the LFP rate trend of each demographic group, and the population shares by age and gender. Dashed lines denote two standard error bounds based on the smoothed posterior estimates from the Kalman filter. 
Figure 5: Unemployment Rate Trend

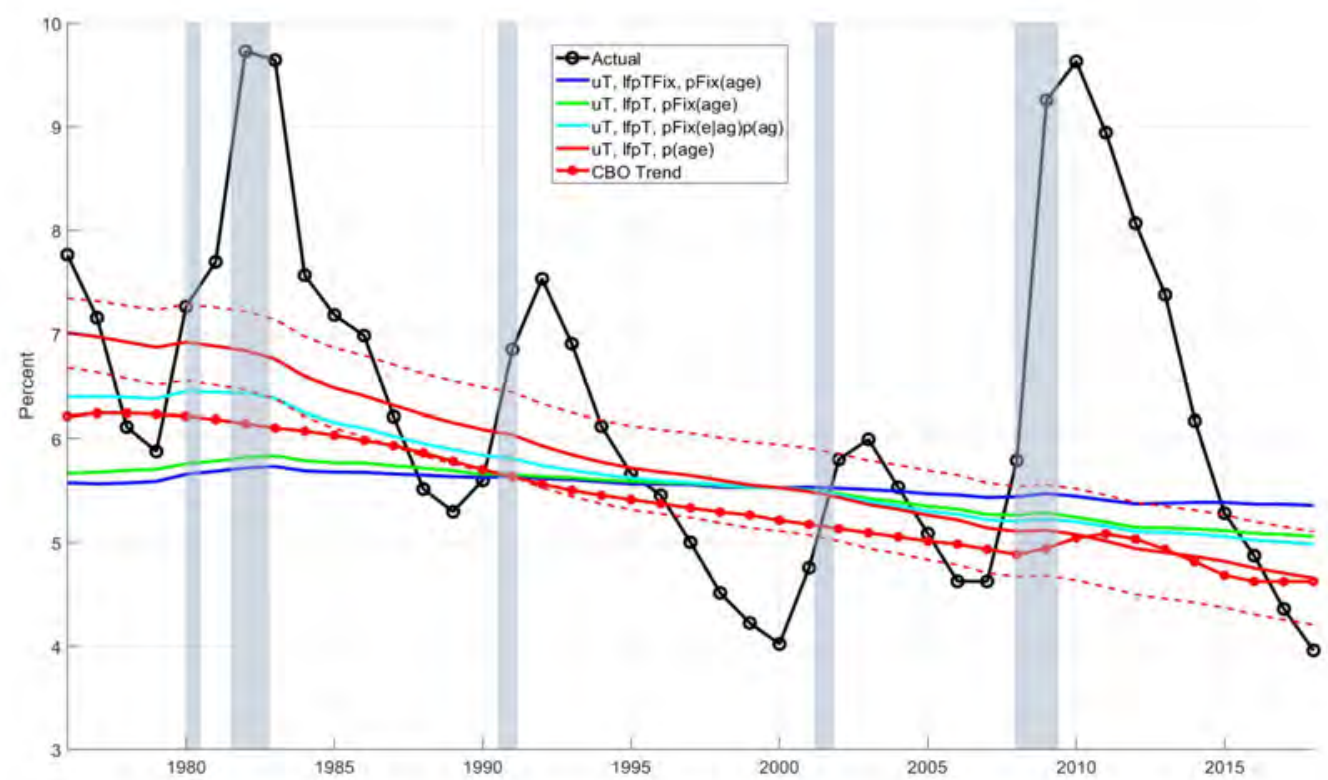

Note: The dark blue line fixes the trend LFP rate and the population shares by age, gender, and education at their 2000 values and allows for variation of the unemployment rate trend of each demographic group. The green line fixes the population shares at their 2000 values and allows for variation of the unemployment rate and LFP rate trends of each demographic group. The light blue line fixes the education distribution conditional on age and gender at its 2017 values and allows for variation of the unemployment rate and LFP rate trends and the population shares of each demographic group. The red line is the trend and allows for variation in the trend values of the unemployment rate and LFP rate and the population shares of demographic groups. The red dotted line is the CBO natural rate estimate. The dashed red lines denote a two standard deviation error band for the trend based on the smoothed posterior estimates from the Kalman filter. 
Figure 6: Cohort Effects for Educhtion Shares
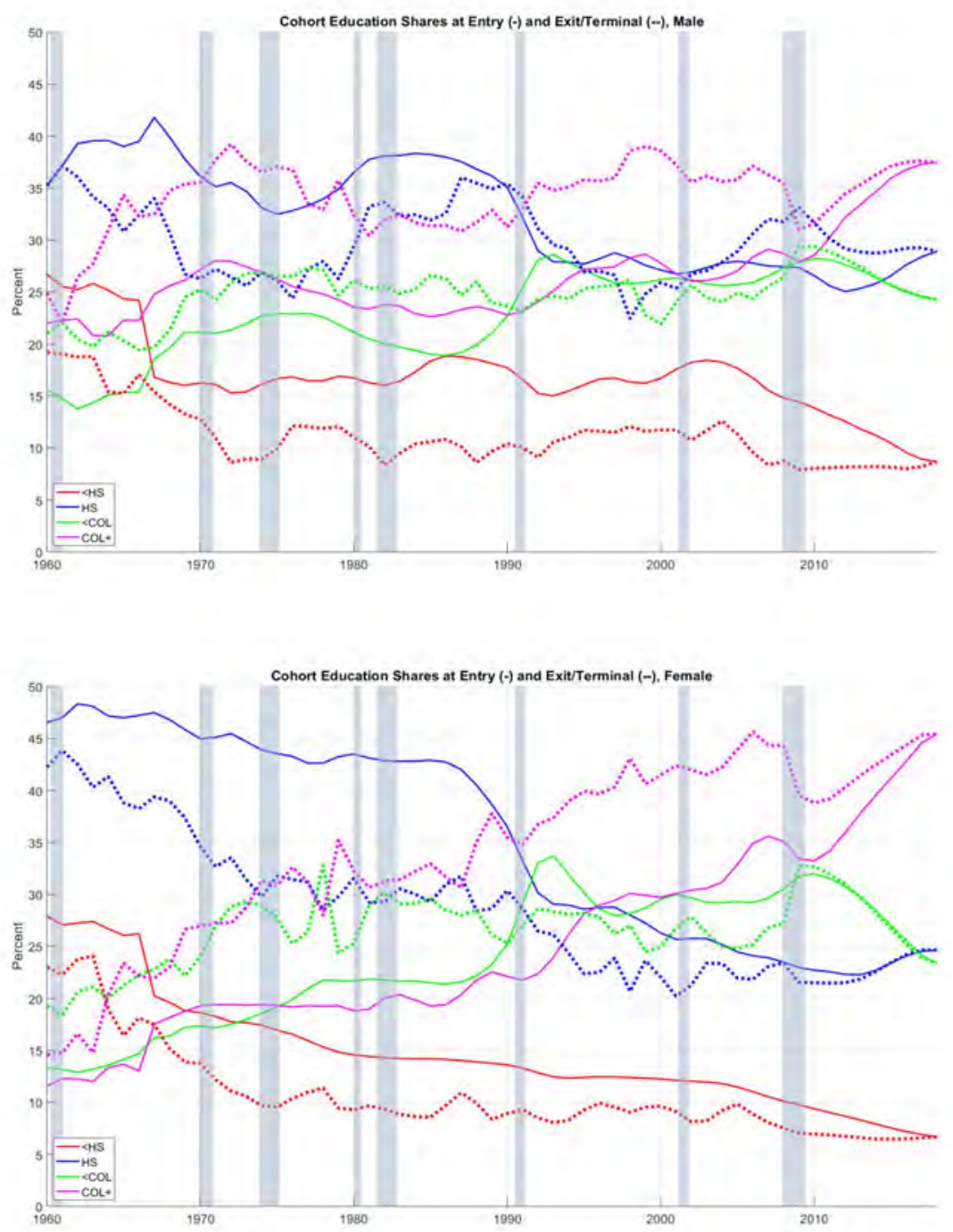

Note: Solid lines denote the education share at the time a cohort enters the sample and dashed lines denote the education share at the end of the sample or at the time the cohort exits the sample. 
Figure 7: Trend LFP Rate with Alternative Cyclical Indicators

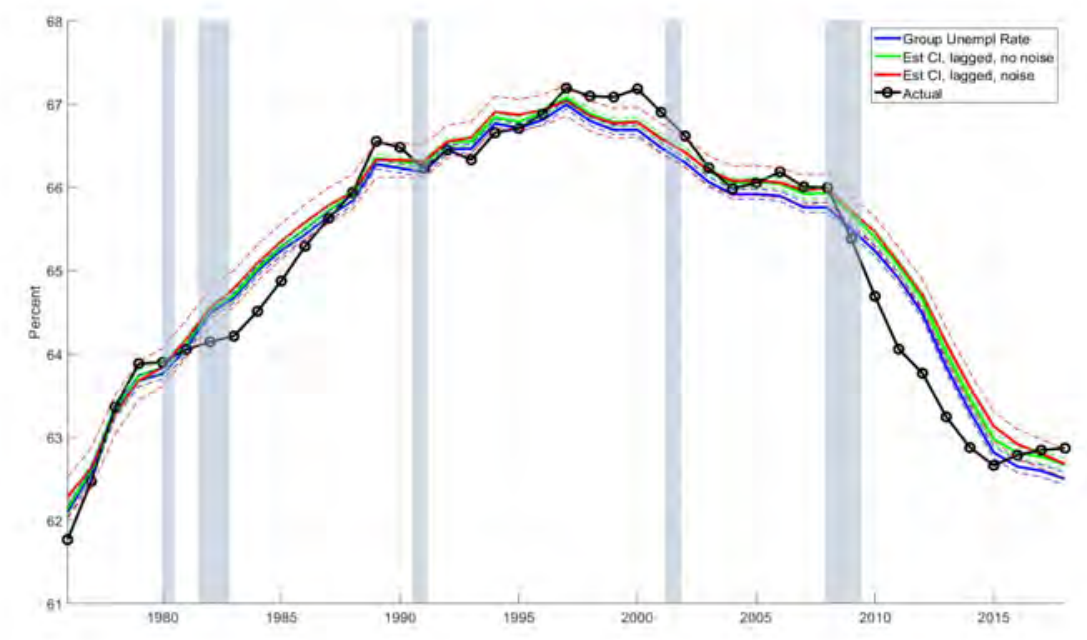

Note: Solid colored lines represent estimates of the trend LFP rate using different models of the cyclical effect correction. The light dashed lines represent the two standard error bands. The cyclical effects are defined specific to gender-education groups. The blue line uses a demographic groups average unemployment rate as the CI, and the green and red line use the estimated CI for the groups trend unemployment rate model. The green line takes the $\mathrm{CI}$ as known and the red line assumes that the CI is a noisy signal of the true CI. 
Figure 8: Long Run CorRelations
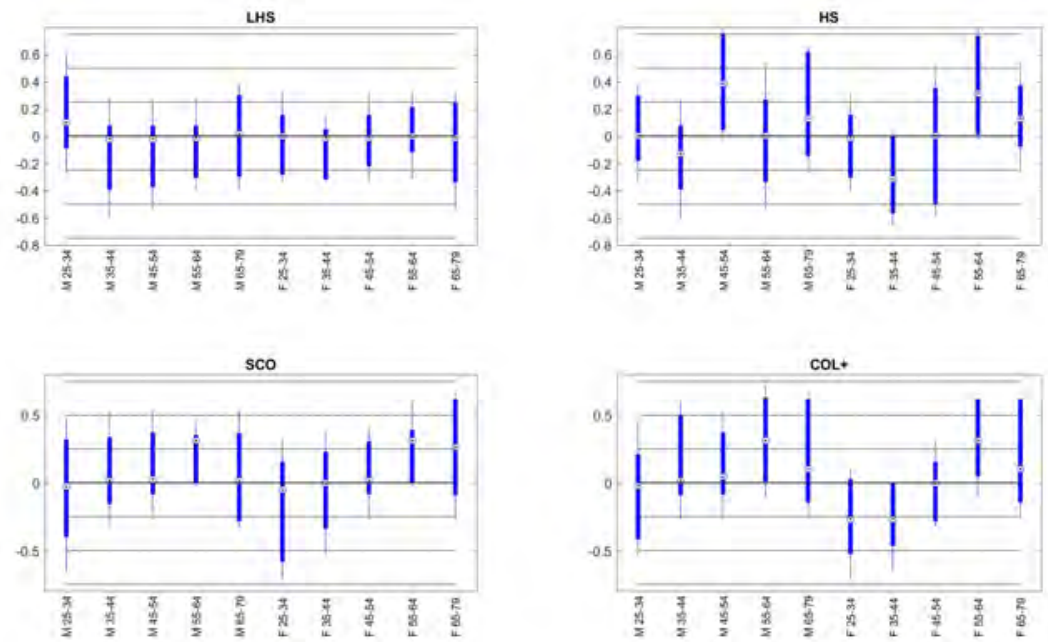

Note: Posterior median (circle) and 67\% (thick bar) and 90\% (thin whisker) confidence intervals for the long run correlation between a demographic group's unemployment rate and its labor force share.

Figure 9: Projections of Education Shares for Males with a High School EduCATION

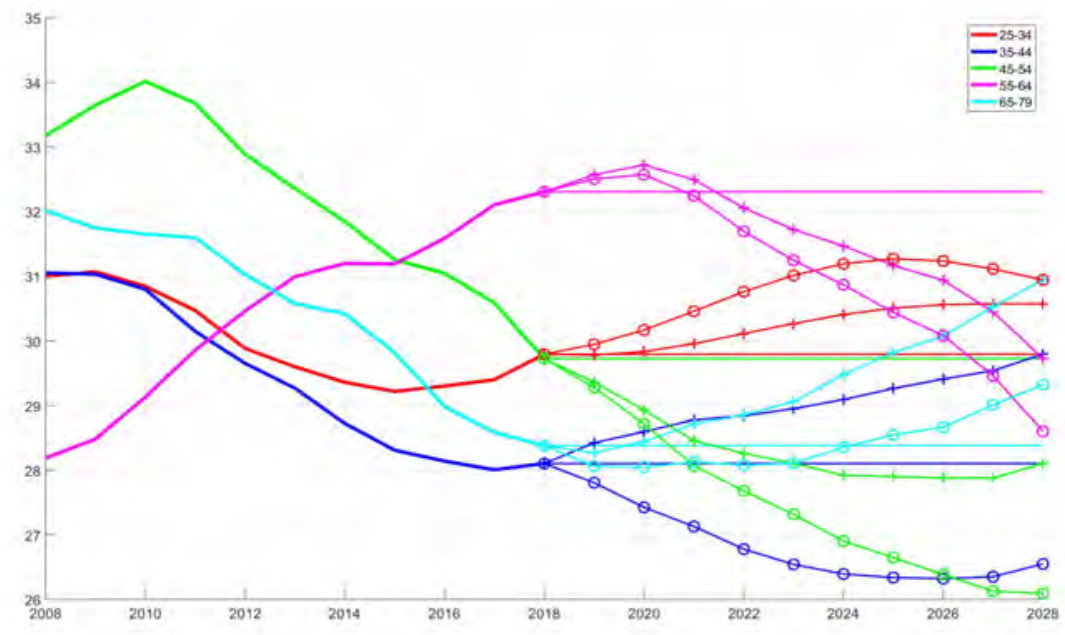

Note: Solid lines prior to 2019 denote the actual education shares of the different age groups. The light solid lines denote projections for future education shares assuming that the education shares remain unchanged at their 2018 values or they evolve according to the cohort model without $(+)$ or with (o) deterministic drift. 